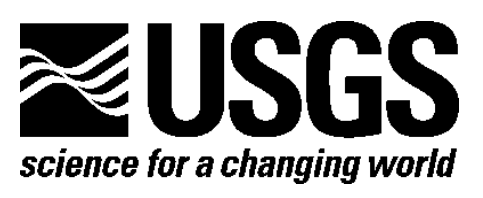

\title{
USGS Methodology for Assessing Continuous Petroleum Resources
}

By Ronald R. Charpentier and Troy A. Cook

Open-File Report 2011-1167

U.S. Department of the Interior

U.S. Geological Survey 


\section{U.S. Department of the Interior \\ KEN SALAZAR, Secretary}

\section{U.S. Geological Survey \\ Marcia K. McNutt, Director}

U.S. Geological Survey, Reston, Virginia 2011

For product and ordering information:

World Wide Web: http://www.usgs.gov/pubprod

Telephone: 1-888-ASK-USGS

For more information on the USGS-the Federal source for science about the Earth, its natural and living resources, natural hazards, and the environment:

World Wide Web: http://www.usgs.gov

Telephone: 1-888-ASK-USGS

Suggested citation:

Charpentier, R.R., and Cook, T.A., 2011, USGS Methodology for Assessing Continuous Petroleum Resources: U.S. Geological Survey Open-File Report 2011-1167

Any use of trade, product, or firm names is for descriptive purposes only and does not imply endorsement by the U.S. Government.

Although this report is in the public domain, permission must be secured from the individual copyright owners to reproduce any copyrighted material contained within this report. 


\section{USGS Methodology for}

Assessing Continuous Petroleum Resources

Ronald R. Charpentier \& Troy Cook

U.S. Geological Survey

charpentier@usgs.gov tcook@usgs.gov 


\section{Outline}

- Principles of resource assessment

- Previous methods of assessing continuous resources

- Methodology issues addressed by the revised USGS methodology 


\section{Outline (continued)}

- Revised USGS methodology for assessing continuous resources

- Defining shale-gas assessment units (AU)

- Walk through the revised USGS methodology

- Applying analog data in data-poor AUs

- Data requirements for shale-gas AUs 


\section{Principles of Resource Assessment}

- Resource assessments should be fundamentally based on geology.

- Probabilistic methods should be used.

- Assessment methodology is a means of quantifying geologic hypotheses and uncertainties. 


\section{Previous Methods of Assessing Continuous Resources}




\section{In-Place Methods}

- Volumetric calculation

- Area * thickness * porosity * hydrocarbon saturation * temperature/pressure corrections

- Recovery factors generally conjectural

- Primary method used by the assessment community prior to 1995

- Still used extensively outside USGS

Commonly, the recovery factors for continuous accumulations have been poorly understood. 


\section{Productivity-Based Methods}

- Based on productivities of cells

- Cells are roughly the size of the drainage area of a well

- Well productivities determined by declinecurve analysis

- Estimated ultimate recovery (EUR)

Productivity-based methods use drilled wells as "computers" to calculate recoverable resources. 


\section{Creating an EUR from a Decline Curve}

Natural Gas Production Fit and Forecast

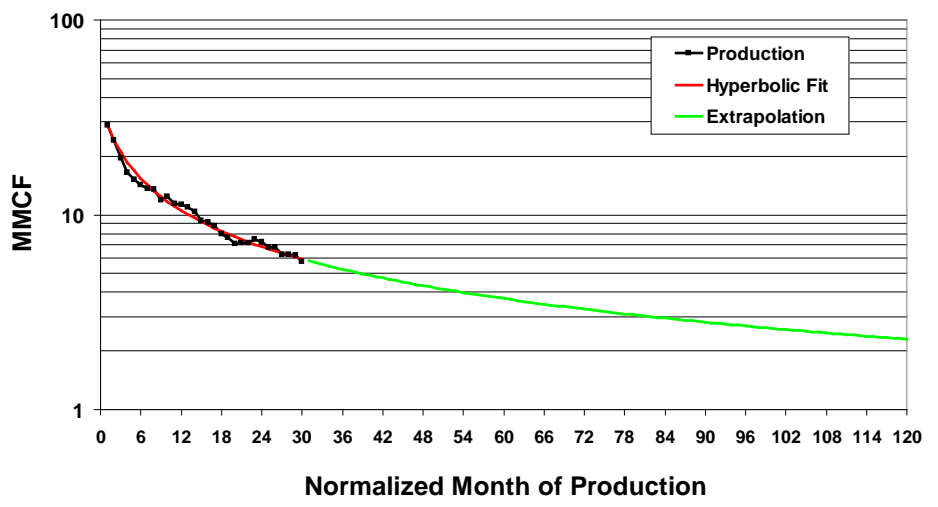

A hyperbolic decline curve was fitted to the mean production decline of six Barnett Shale gas wells. This example demonstrates a calculation of estimated ultimate recovery (EUR) based on a 90-month forecast of the expected decline. 


\section{Productivity-Based Methods}

- Estimates of numbers of cells based on:

- Area of assessment unit (AU)

- Percent of area already tested

- Area of a cell

- In USGS methodology, all of these are estimated as probability distributions 


\section{Advantages of Productivity-Based Methods}

- Well productivities (EURs) make assessments more realistic

- Much more production data available now compared to 30 years ago

- Many more wells with longer producing histories

- Many more plays 


\section{Disadvantages of Productivity-Based Methods}

- Assessments are tied to current engineering practice.

- No estimate of volumes recoverable by future technologies

- Large data requirements

Some organizations that need to study the effect of radical changes in production technology may wish to supplement these methods with in-place calculations. Although the methods have large data requirements, analog data can be used for areas that are data-poor. 


\section{Methodology Issues Addressed by the Revised USGS Methodology}




\section{Applicable to Frontier Assessment Units (AUs)}

- No or little previous production

- Little information about well performance parameters

- Success ratios

- Drainage areas

- Estimated ultimate recoveries (EURs)

- Possibility of zero potential

- Solved by use of analogs 


\section{Accounts for Poorly- Developed Geologic and Engineering Models}

- Understanding of geologic and engineering controls on productivity is not as refined as for conventional petroleum.

- Still very hard to estimate ahead of drilling

- Great improvements in last decade

- Lots of models giving partial explanations of controls on productivity

- Revised method is robust. 


\section{Better Handling of Complex Historical Information}

- Complex patterns

- For example, trends in EUR with time

- Not as "well behaved" as some classic conventional data sets

- Discovery process models less applicable

- Multiple trends going on at once

- Analysis and interpretation needed 


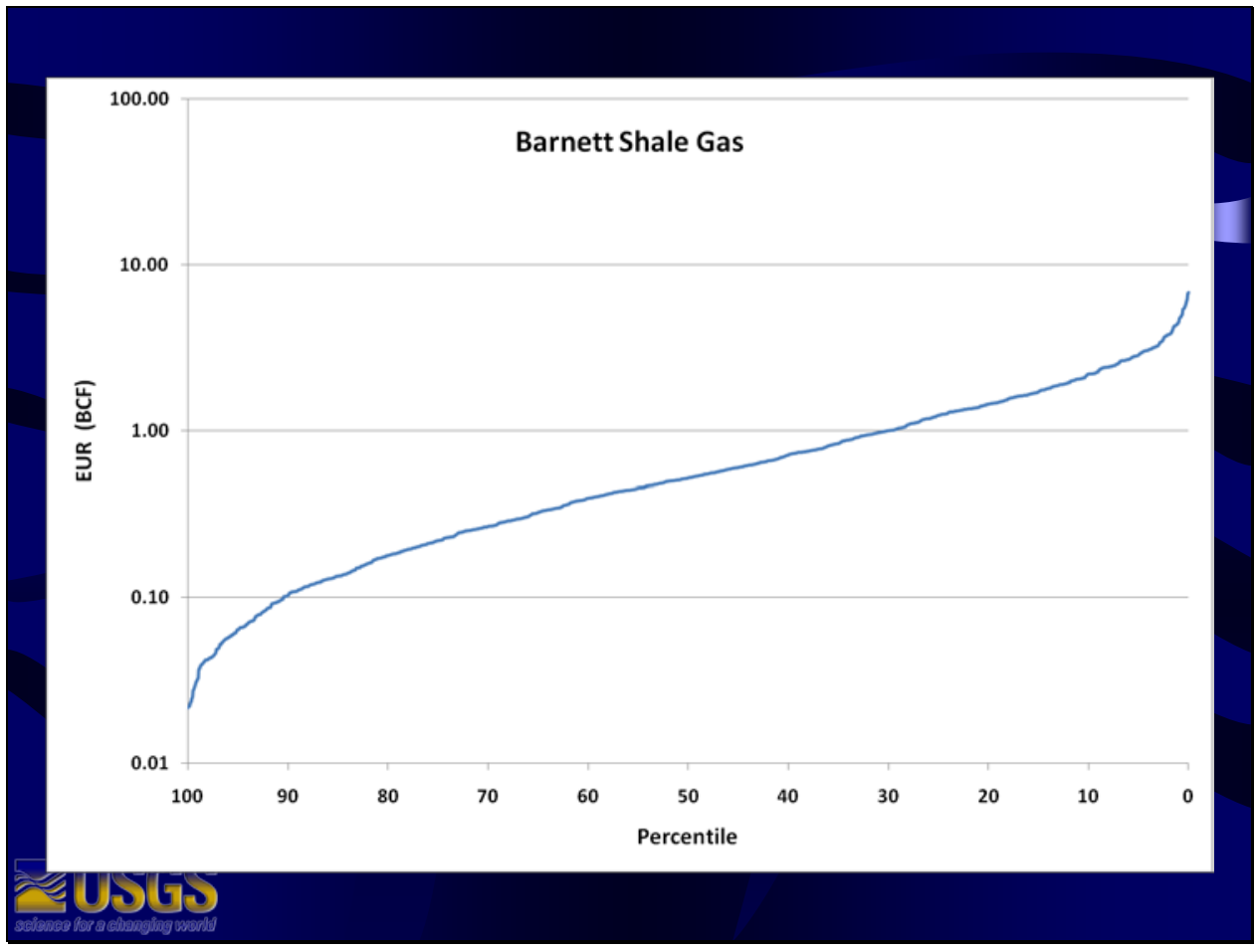

This graph presents the EUR for 1,417 vertical wells in the Barnett Shale as of 2003. It shows the distribution of EURs for those wells with an EUR of at least 0.02 billion cubic feet (bcf). The percentiles indicate what percent of the wells have an EUR of at least the indicated amount. Note that the range of EURs is greater than two orders of magnitude. ( 1 billion cubic feet $=$ approximately 28 million cubic meters). 


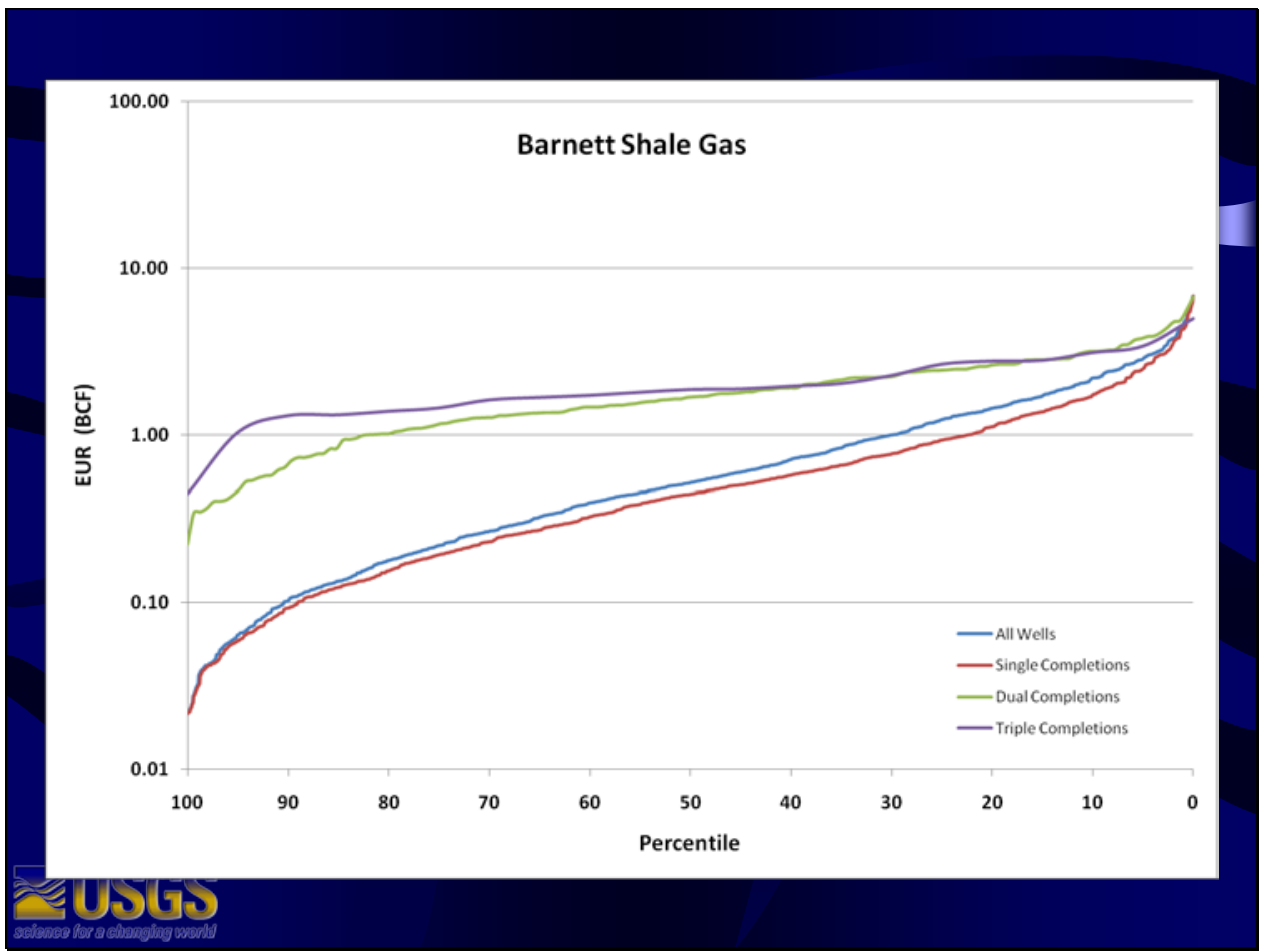

This graph adds lines for those wells used in the preceding graph with single completions $(1,240)$, dual completions (156), and triple completions (21). 


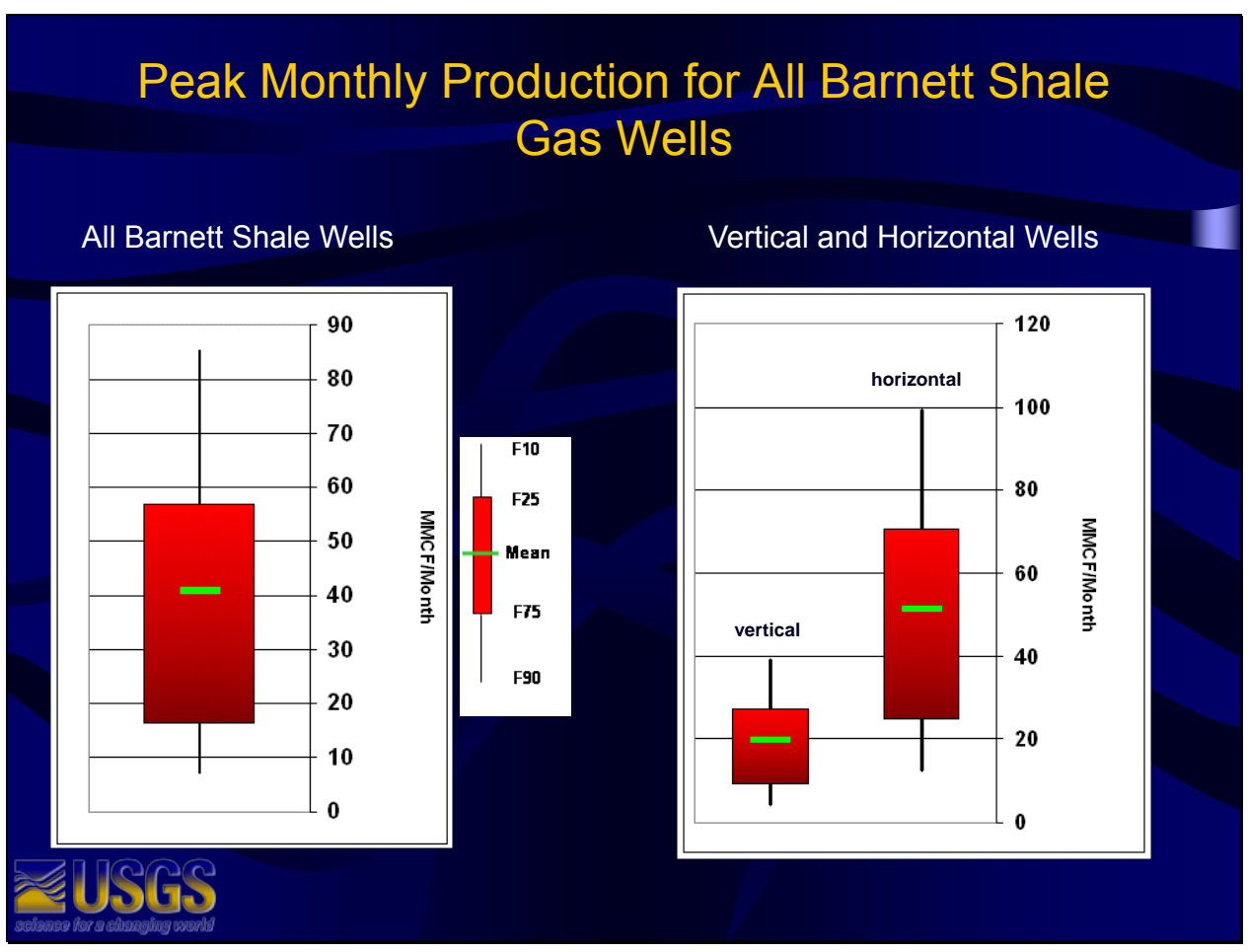

These box-and-whisker plots show the distribution of peak monthly production for Barnett Shale vertical wells as of 2003. Peak monthly production is generally the production value for the first full month of production. Note the increase in information that results when the full distribution (on the left) is broken into two subgroups (on the right) showing much higher peak monthly production values for horizontal wells as compared to vertical wells. The box-and-whiskers plots show the parameters of the distributions: the green line is the mean, the top and bottom of the red box are the F25 and F75 fractiles, and the top and bottom of the lines are the F10 and F90 fractiles. MMCF, million cubic feet. 


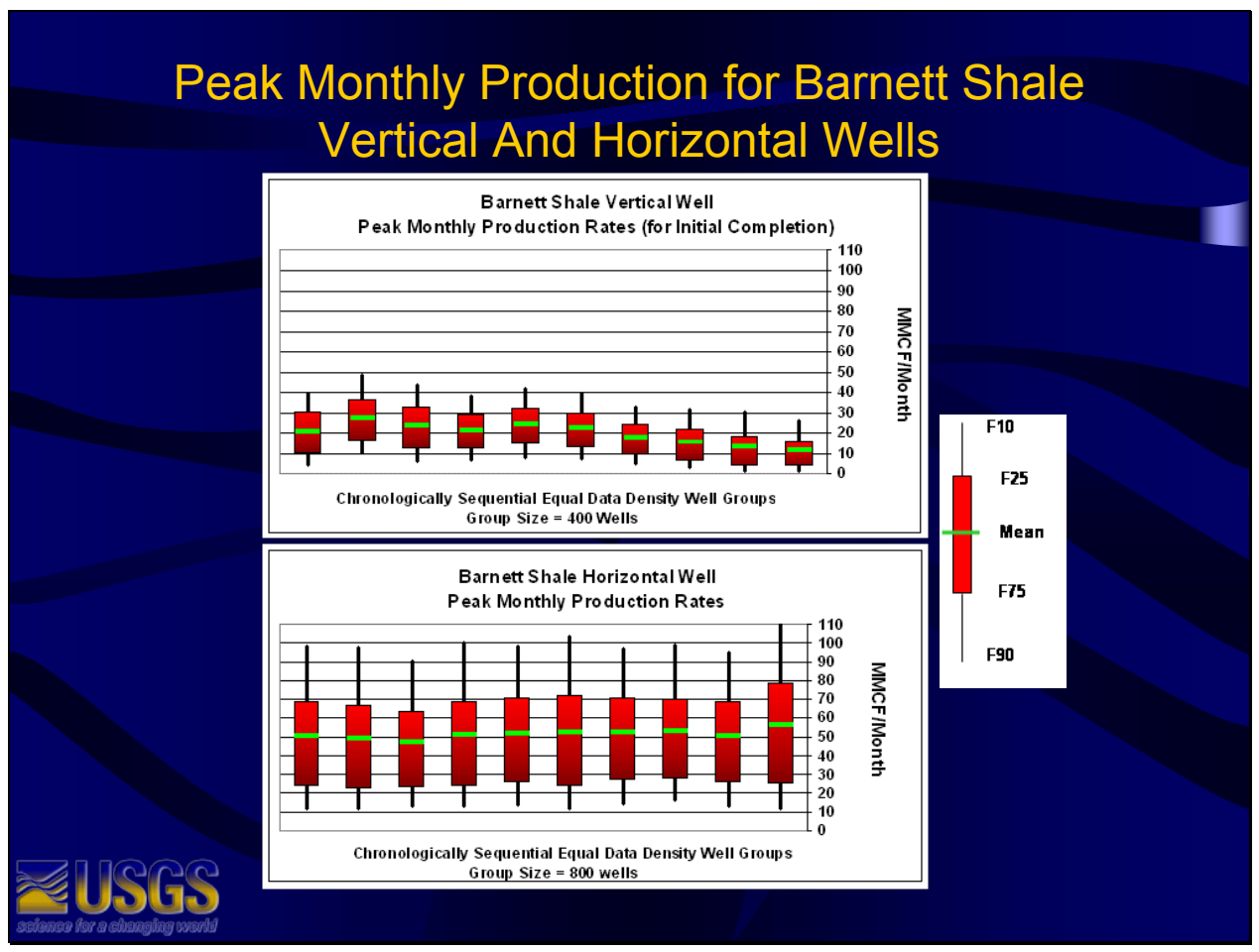

The same data from the previous slide can be further subdivided to give even more information. Here the wells are divided into subgroups by order of drilling to show trends in peak monthly production with time. Vertical wells show a decrease with time, whereas horizontal wells have had relatively stable peak monthly production with time. 


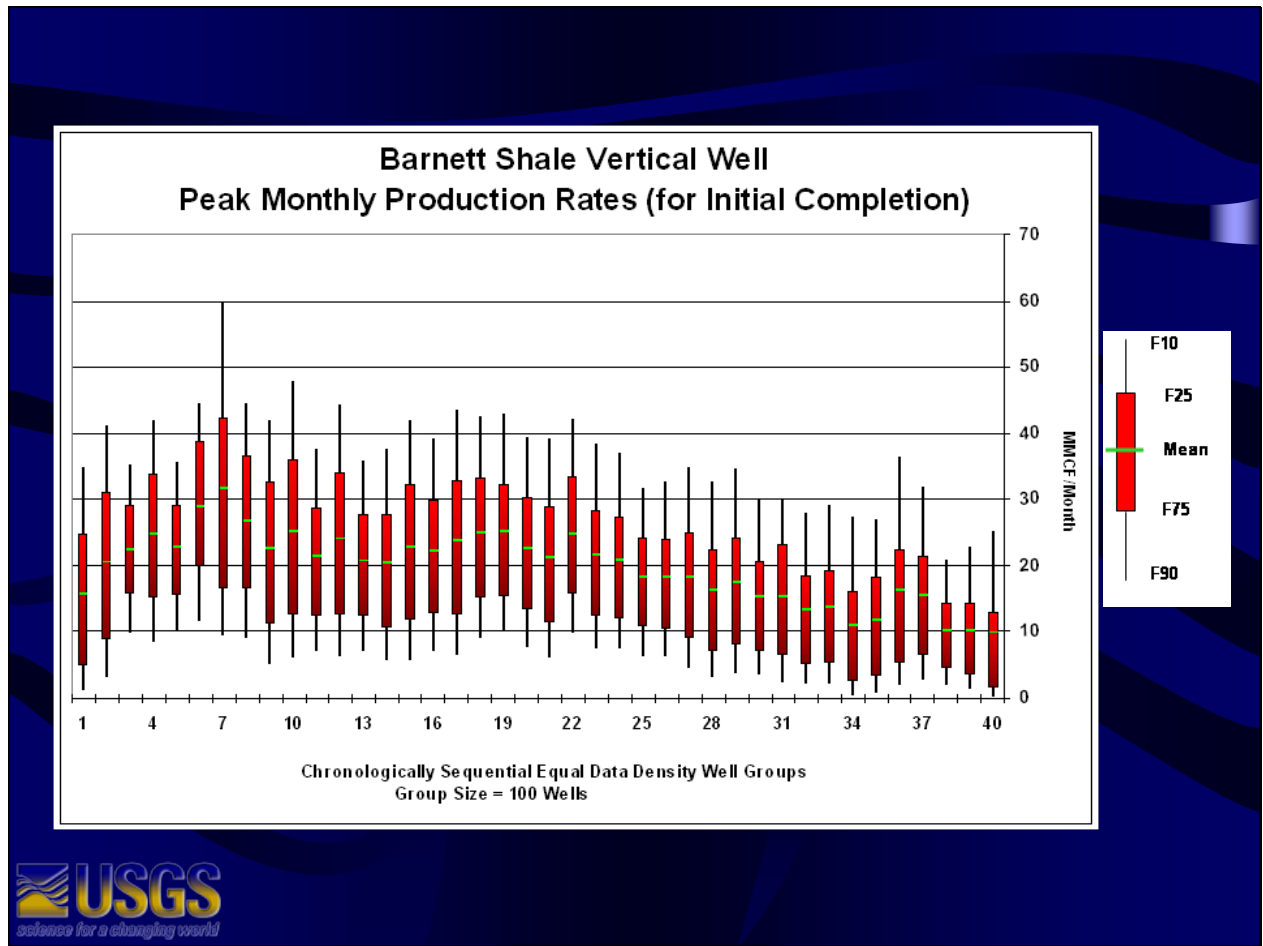

Even more subdivision provides additional information on data trends. 


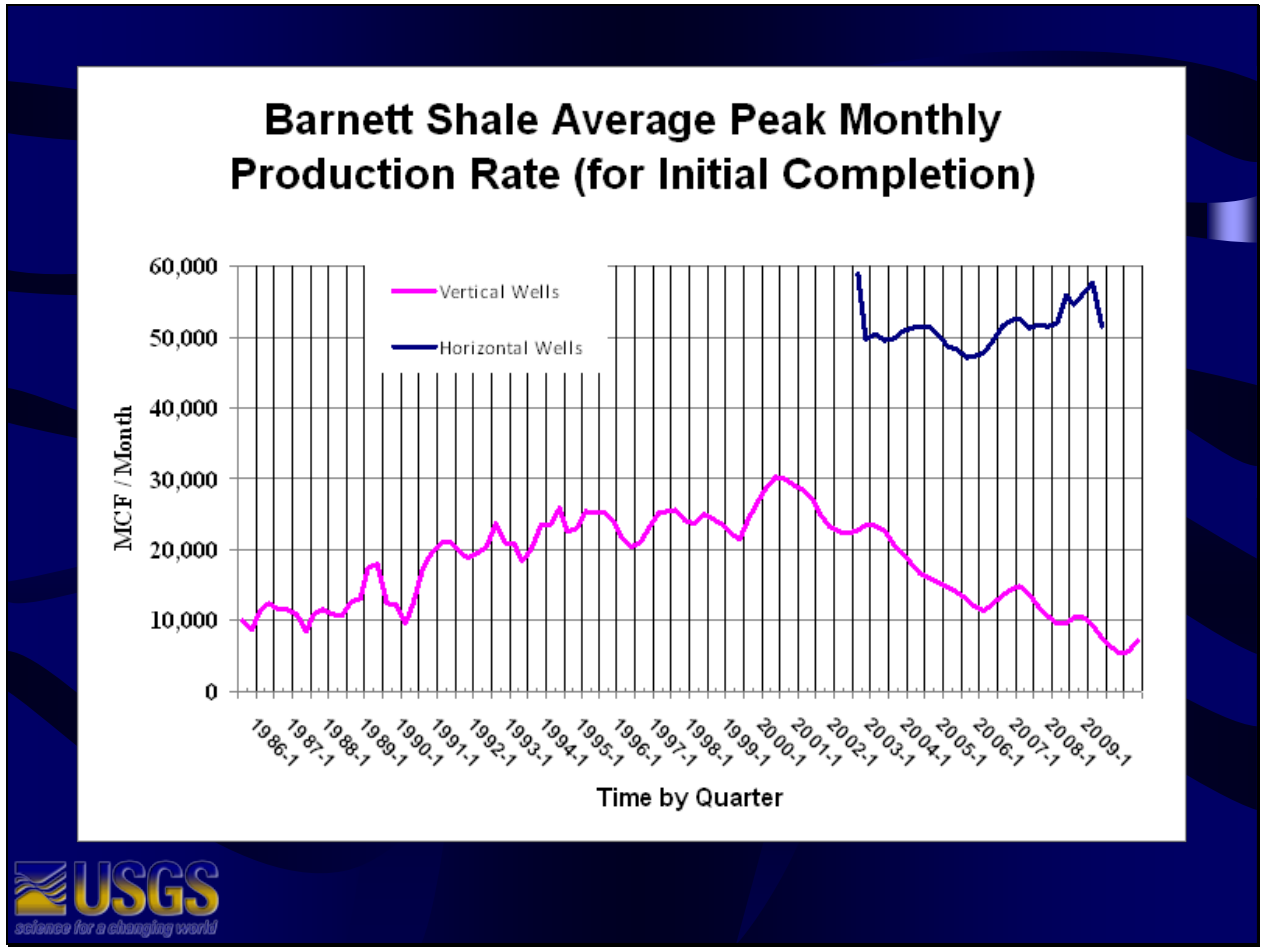

This graph shows trends in the average peak monthly production with time, separately for vertical and horizontal wells. MCF, thousand cubic feet. 


\section{Allows Mixture of Sweet and Nonsweet Populations}

- Study of some continuous deposits suggests that the productivities within a continuous deposit are a mixture of two populations

- Most clearly seen in some tight gas sands

- Not all deposits show this

- How do you define sweet?

- Are sweet spots just the high end of some distribution, or are they evidence of a mixture? 


\section{Barnett Shale Wells, circa. 2001}

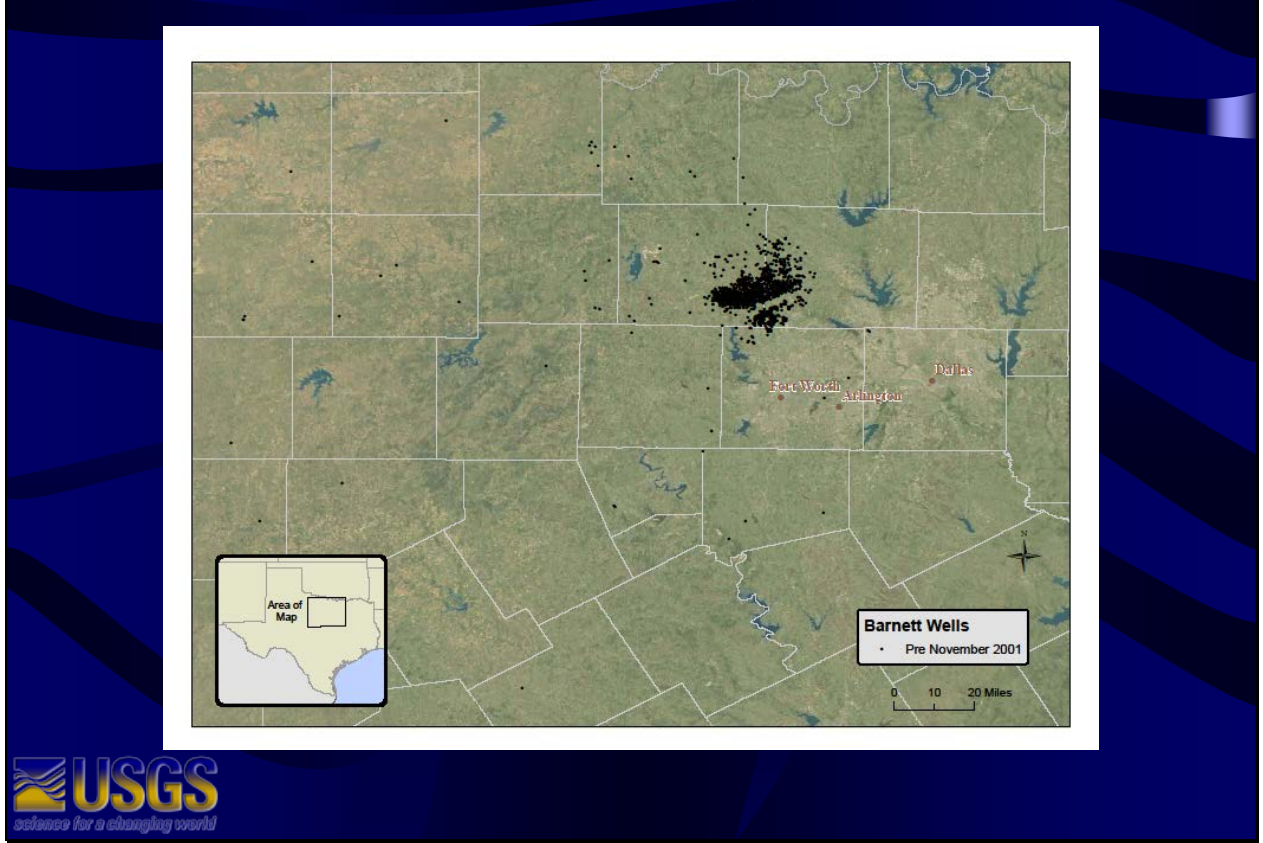

The spatial distribution of well productivity reflects spatial changes in those geologic and engineering characteristics that control the productivity. This map shows vertical wells drilled in the Barnett Shale as of 2001, defining a sweet spot. (20 miles = approximately 32 kilometers). 


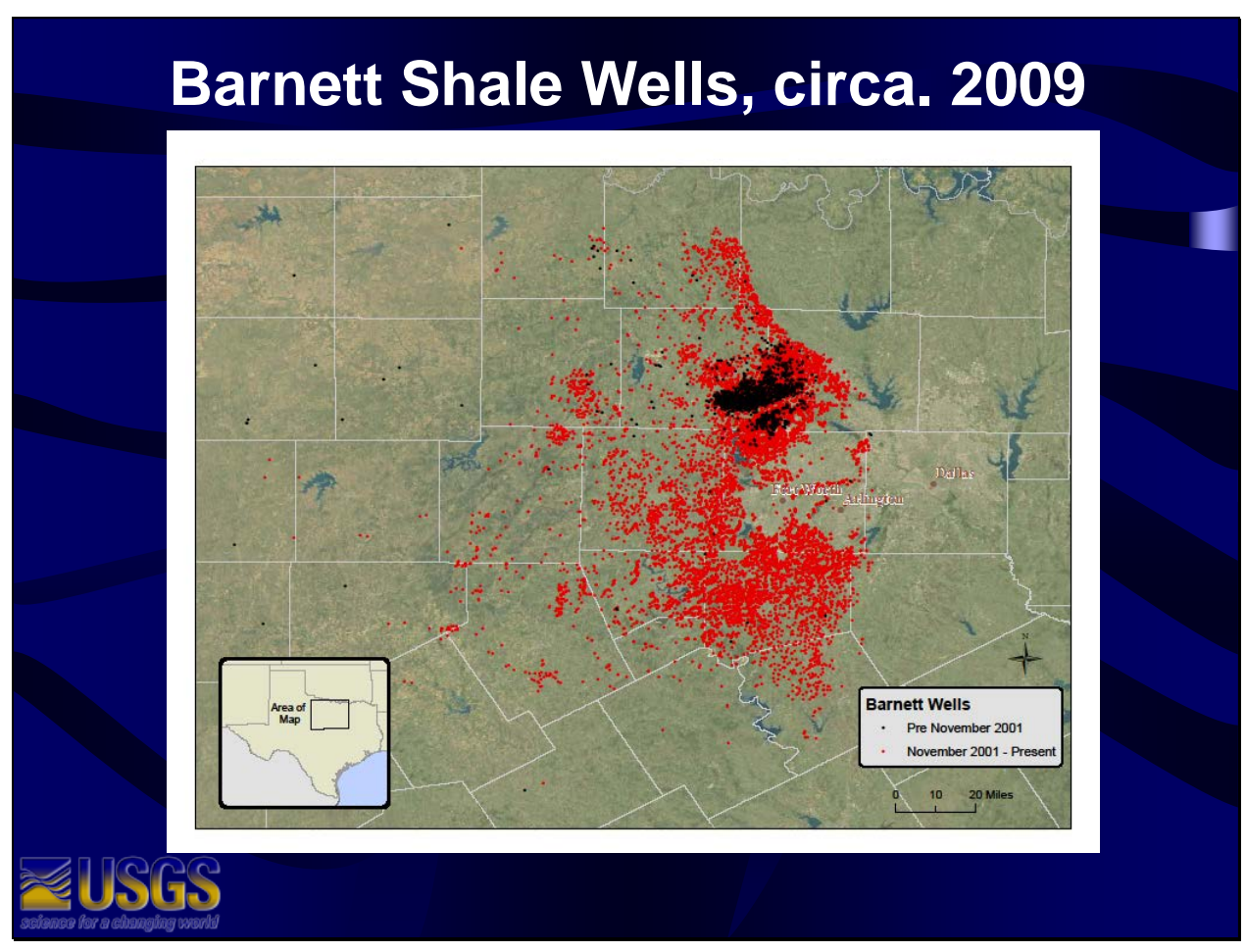

This map shows a great expansion of the Barnett play that took place between 2001 and 2009 . Most of the new wells were horizontal wells. 


\section{Fixes the Problem of EUR Distribution "Collapse"}

- A major methodological problem for assessing continuous resources is the effect on the EUR distribution of using thousands of cells/wells.

- Same result as if a single mean EUR value was used instead of an EUR distribution

- EUR distribution "collapses" around the mean.

When assessment models aggregate thousands (or tens of thousands) of EURs from an EUR distribution, the result is close to merely multiplying the number of cells by the mean EUR. 


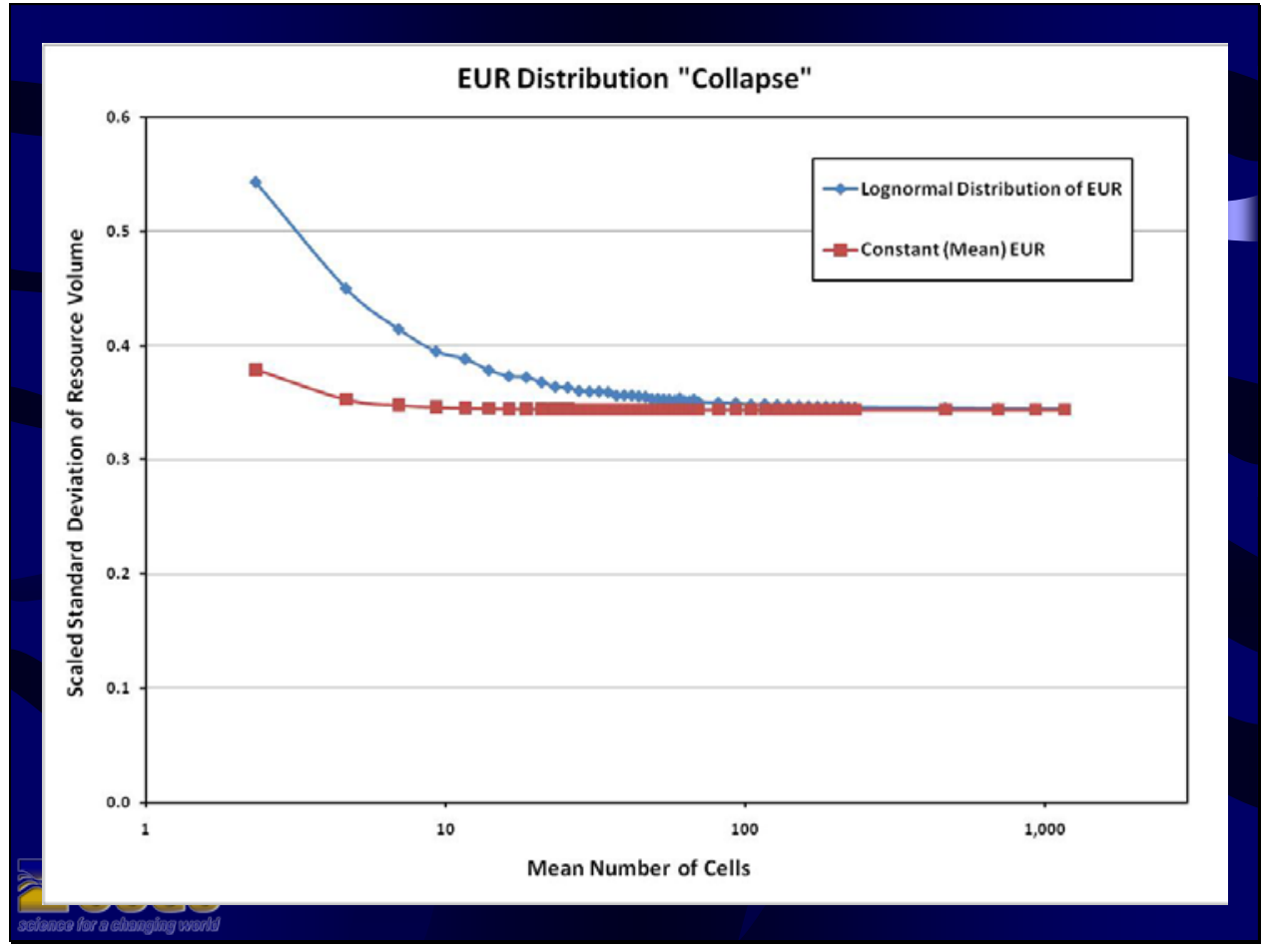

This graph shows a comparison of simulations performed with a shifted truncated lognormal distribution of EURs versus simulations with a constant mean EUR. When there are more than 100 cells, the standard deviation of the resulting estimate of gas volume is practically the same whether a variable or a constant EUR is used. Most assessments are for thousands or tens of thousands of cells. This phenomenon is termed EUR distribution "collapse" around the mean. 


\section{Fixes the Problem of EUR Distribution "Collapse"}

- Older methodology thus acts as if the mean of the EUR distribution was known exactly.

- In frontier AUs, the uncertainty about the mean EUR is a major part of the uncertainty in the estimate.

- Revised methodology directly estimates the uncertainty of the mean EUR.

The older assessment model acts as if the mean were known exactly. This underestimates the uncertainty in the result, especially for frontier AUs where the mean EUR is uncertain. 
Revised USGS Methodology

for Assessing

Continuous Resources 


\section{Features of Revised USGS Methodology}

- Wells instead of cells

- Risk more explicit

- AU risk, area risk, well risk

- Option to have mixture of two populations

- Sweet spots and nonsweet spots

- Direct estimation of uncertainty of mean EUR 


\section{Robustness of Revised USGS Methodology}

- The revised methodology works for both datarich and data-poor areas.

- Analogs used for data-poor areas

- The revised methodology is not tied to a specific geologic model.

- As better understanding of geologic and engineering controls develops, this can be accommodated in the assessments. 


\section{Defining Shale-Gas Assessment Units}

Before conducting a quantitative assessment, one must define assessment units and select which ones will be quantitatively assessed. A set of minimum requirements is needed to determine which proposed units may have significant resources to assess. These criteria are also used in the quantitative assessment itself. As an example, the minimum requirements for shale-gas assessment units are presented here. 


\section{Minimum Requirements}

- Based on current USGS thinking of what is needed to have a successful shale-gas AU

- Could change in the future with increased geologic understanding

- This list is specific to thermally generated gas in its source rock.

- Biogenic gas would have different minimum requirements. 


\section{Minimum Requirements}

- TOC $>2$ weight percent

- Kerogen type I, II, or IIS

- Ro > 1.1 percent

- Net thickness $>15$ meters

- Gas is thermogenic

TOC, total organic carbon; Ro, vitrinite reflectance. 


\section{Desirable Characteristics}

- High gamma-ray values in shale

- Hydrogen index of kerogen greater than 250 $\mathrm{mg} / \mathrm{g}$

- Depth greater than 1,500 meters

- Not intensely structured

- Overpressured

$\mathrm{Mg} / \mathrm{g}$, milligrams per gram. 


\section{Walk Through of the New USGS Methodology}




\section{AU Risk}

- Based on 5 minimum requirements

- What is the probability that all 5 requirements are met at some place within the AU?

- This shows the need for mapping the extents of the 5 requirements. 


\section{AU Risk - Alternate Questions}

- What is the probability that at least one well within the AU will have production capacity of at least the minimum EUR (0.02 bcf)?

- What is the probability that the petroleum system exists?

- Conversely, what is the probability that the AU will have no producible resources? 


\section{AU Risk}

Assessment-Unit Probability:

an accumulation with producible resources exists?

This is the part of the official input form that concerns AU risk. 


\section{Line 1 - Productive Area}

- Again, based on 5 minimum requirements

- How large is the area within the AU where all 5 requirements are met?

- This shows again the need for mapping the extents of the 5 requirements, and understanding the uncertainties about their extents. 


\section{Line 1 - Productive Area}

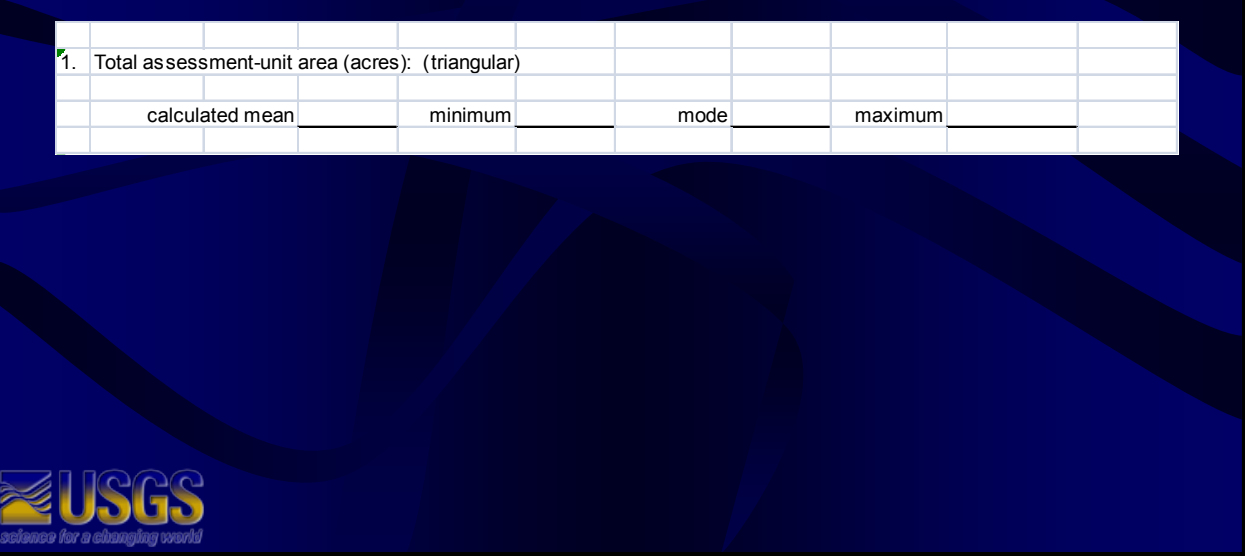

In this line and others, the distribution represents the assessors' uncertainty about a single value that exists in nature. (There exists one correct value of how large an area meets the five minimum requirements.) Distributions in nature are rarely triangular, but this is a distribution within the minds of the assessors. The minimum, mode, and maximum values of a triangular distribution are reasonable values to ask of an assessor to describe his/her uncertainty. 


\section{Line 2 - Drainage Areas}

- What is the average drainage area of a production well in this AU?

- Uncertainty about a fixed value

- Contingent on a development scheme

- Horizontal vs vertical wells

- Development scheme must be consistent with that implied by the EUR distribution 


\section{Line 2 - Drainage Areas}

2. Uncertainty about average drainage area of wells (acres): (triangular) calculated mean minimum mode maximum 


\section{Line 3 - Untested Area}

- What percent of the area from line 1 is untested?

- Requires interpretation of previously drilled wells in the interval

- What constitutes a production test?

- Previous wells (perhaps vertical) may have tested less area each than the wells (perhaps horizontal) of the development scheme of line 2 .

Not all penetrations of a stratigraphic interval are tests of that interval. Interpretation of those wells is needed, but the number of tests may be uncertain. Date of drilling may provide information, in that wells drilled before the recognition of production potential in that interval are unlikely to be tests (especially in an underpressured interval). 


\section{Line 3 - Untested Area}

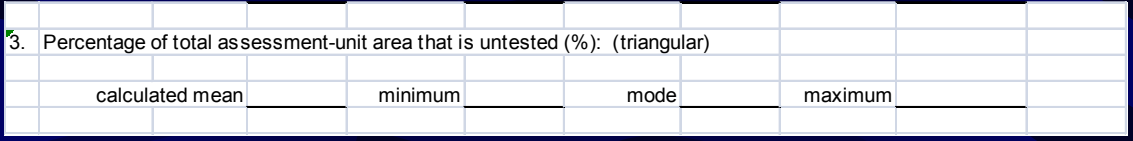




\section{Line 4 - Sweet vs Non-sweet}

- Within the untested area (as defined by lines 1 and 3), what percent of the area falls within sweet spots?

- Can be 100 percent if assessors choose to model the accumulation with one population (one success ratio and one EUR distribution) rather than two 


\section{Line 4 - Sweet vs Non-sweet}

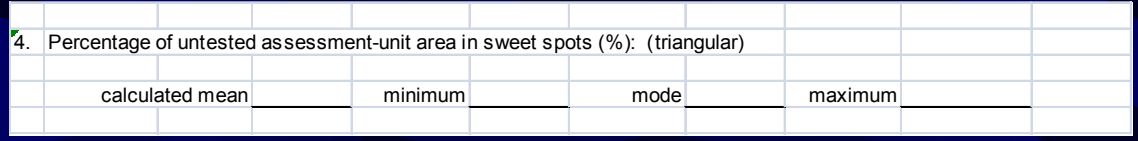




\section{Line $5 a$ - Success Ratio}

- Within the untested sweet spots (as defined by lines 1,3 , and 4 ), what percent of wells will have productivity greater than the minimum?

- Line 6a is the equivalent for the non-sweet spots.

Some of the non-successes would have no or insufficient flow to result in completing the well as a producer. Other non-successes would be completed as producers, but have an EUR less than the minimum. 


\section{Line 5a - Success Ratio}

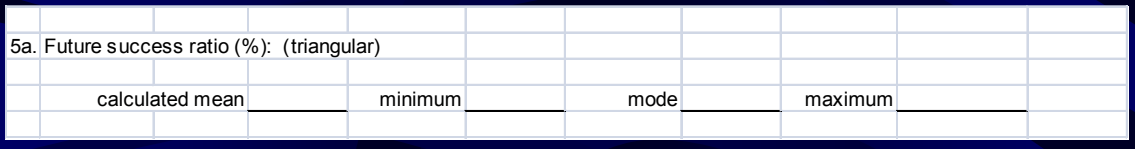




\section{Line 5b - EUR Distribution}

- Within the untested sweet spots (as defined by lines 1,3 , and 4 ), what is the average EUR?

- Uncertainty about a fixed value

- Development scheme must be consistent with that implied by the drainage area

- Line $6 \mathrm{~b}$ is the equivalent for the non-sweet spots.

Experimentation with analog data suggested that the uncertainty about the average EUR could be more skewed that can be reasonably represented by a triangular distribution. Thus a shifted truncated lognormal distribution is used here. 


\section{Line 5b - EUR Distribution}

5b. Uncertainty about average EUR (mmbo for oil; bcfg for gas): (shifted truncated lognormal) calculated mean minimum median maximum

mmbo, million barrels of oil; bcfg, billion cubic feet of gas. 


\section{Coproduct Ratios}

- Each continuous AU has a primary product of either oil or gas.

- Uncertainty about the average ratios

- Oil AU

- Gas to oil ratio

- NGL to gas ratio

- Gas AU

- Liquids to gas ratio

NGL, natural gas liquids. 


\section{Coproduct Ratios}

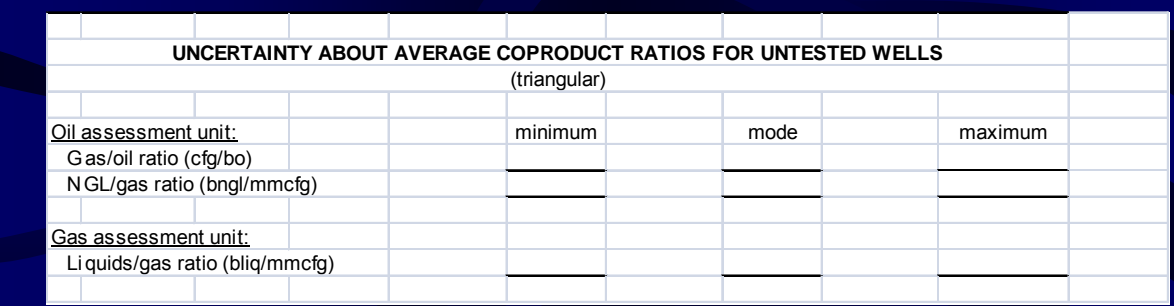

$\mathrm{cfg} / \mathrm{bo}$, cubic feet of gas per barrel of oil; bngl/mmcfg, barrels of natural gas liquids per million cubic feet of gas; bliq/mmcfg, barrels of liquids per million cubic feet of gas. 


\section{Ancillary Data}

- Not used in the volumetric calculations

- Useful for cost analysis or supply modeling 


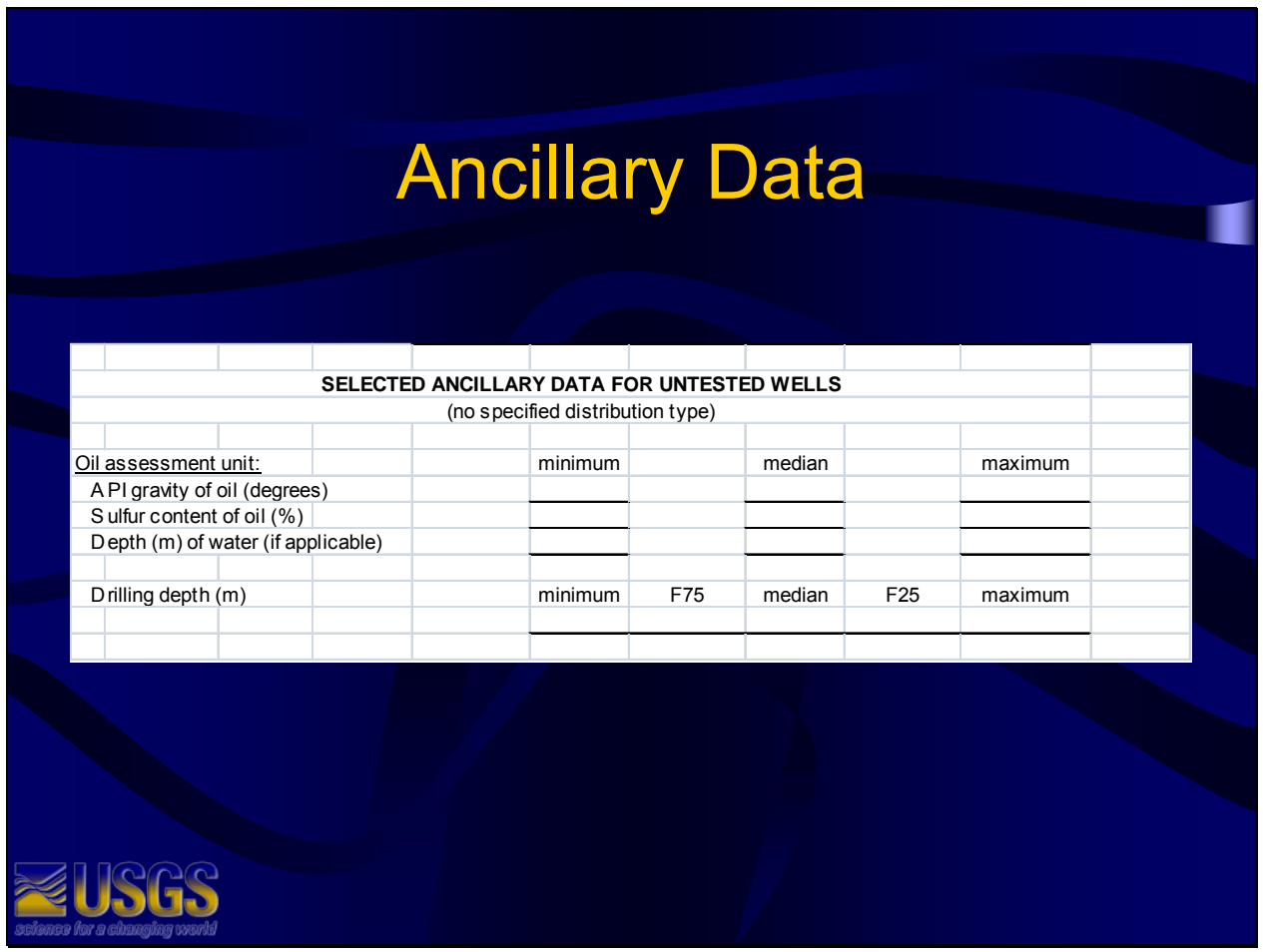

There is a 75 percent chance of the depth being greater than the F75 value. Similarly, there is a 25 percent chance of the depth being greater than the F25 value. 


\section{Allocations}

- Commonly need to report by geographic entity (country, state, province; onshore vs offshore)

- Point estimates of percent of resource volume

- Problems with distributions constrained to add to 100 percent

- Default is to use areal percent determined by GIS 


\section{Allocations}

ALLOCATIONS OF POTENTIAL ADDITIONS TO RESERVES TO STATES Surface Allocations (uncertainty of a fixed value)

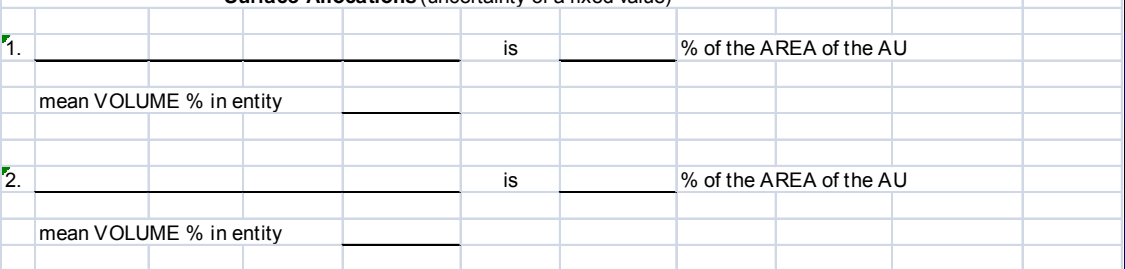




\section{Applying Analog Data in Data-Poor AUs}




\section{EUR Analog Sets}

- For this presentation, preliminary analog sets were built based on the USGS estimates of future EUR distribution for 100+ AUs.

- Analog sets can similarly be built for other well-performance parameters, such as well drainage areas

Of the 100+ AUs for continuous oil and gas resources, 21 shale-gas AUs will be used in the following graphs. 


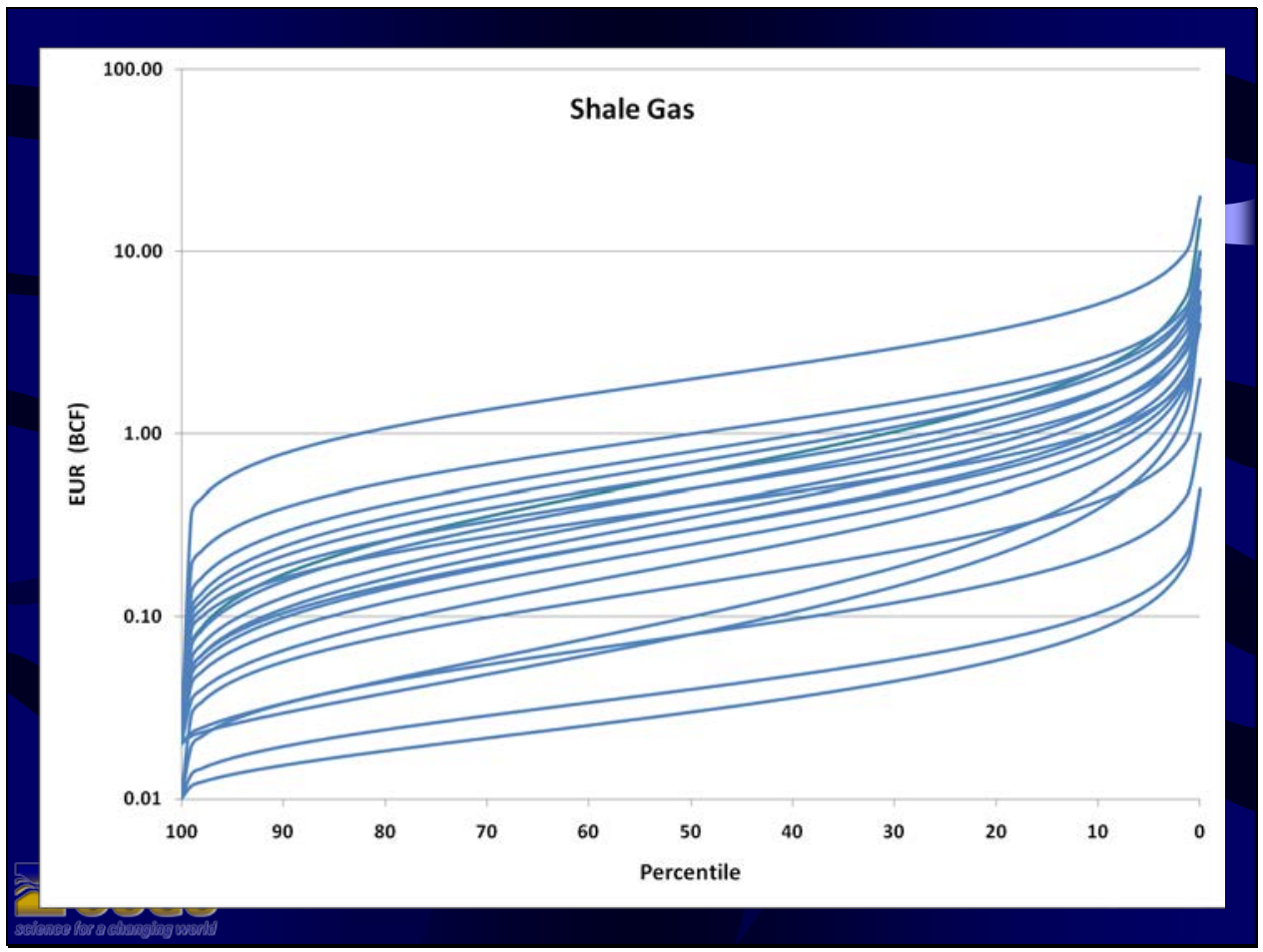

This graph shows 21 shale-gas EUR distributions, based on USGS assessments of undiscovered shale-gas resources. Each distribution is a truncated shifted lognormal, and is therefore a smooth curve. The graph thus represents the "distribution of the distributions." Each distribution is a USGS estimate of the EUR distribution for undrilled productive cells of a particular assessment unit. This graph is termed a "spaghetti plot" which shows how EUR distributions vary for different shale-gas assessment units. The overall area defined by the variation in EUR distributions is termed "the cloud." 


\section{First Generation Analog Set}

- Good approximation of full EUR distribution

- Estimates of future EUR distribution were always close to EUR distribution of previously drilled wells

- Effect of earlier (learning curve) wells minimized

- Effect of geological differences in undrilled areas included

Defining the cloud by using USGS estimates of EUR distributions of undrilled cells gives a good rough approximation of the range of distributions. Assessments have been conducted over the last decade in a wide variety of reservoirs, using a variety of completion practices, and thus the present analog set probably captures much of the range of distributions based on current technology. 


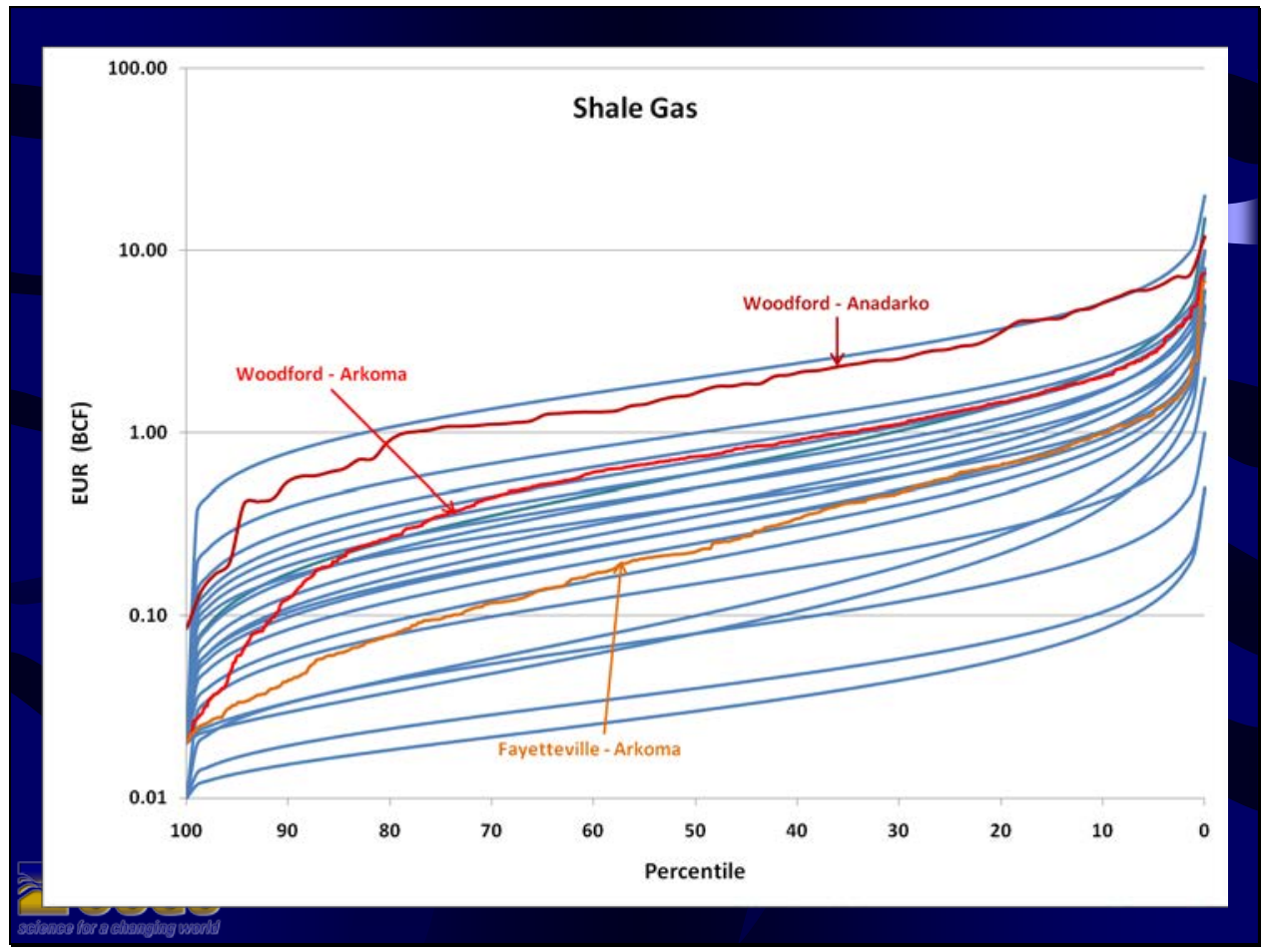

This graph adds the EUR distributions for three recent USGS sets of shale-gas wells, plotted against the cloud shown previously, to put the three distributions in context. The three additional curves are not smooth because they are based on actual well data and not on fitted distributions. 


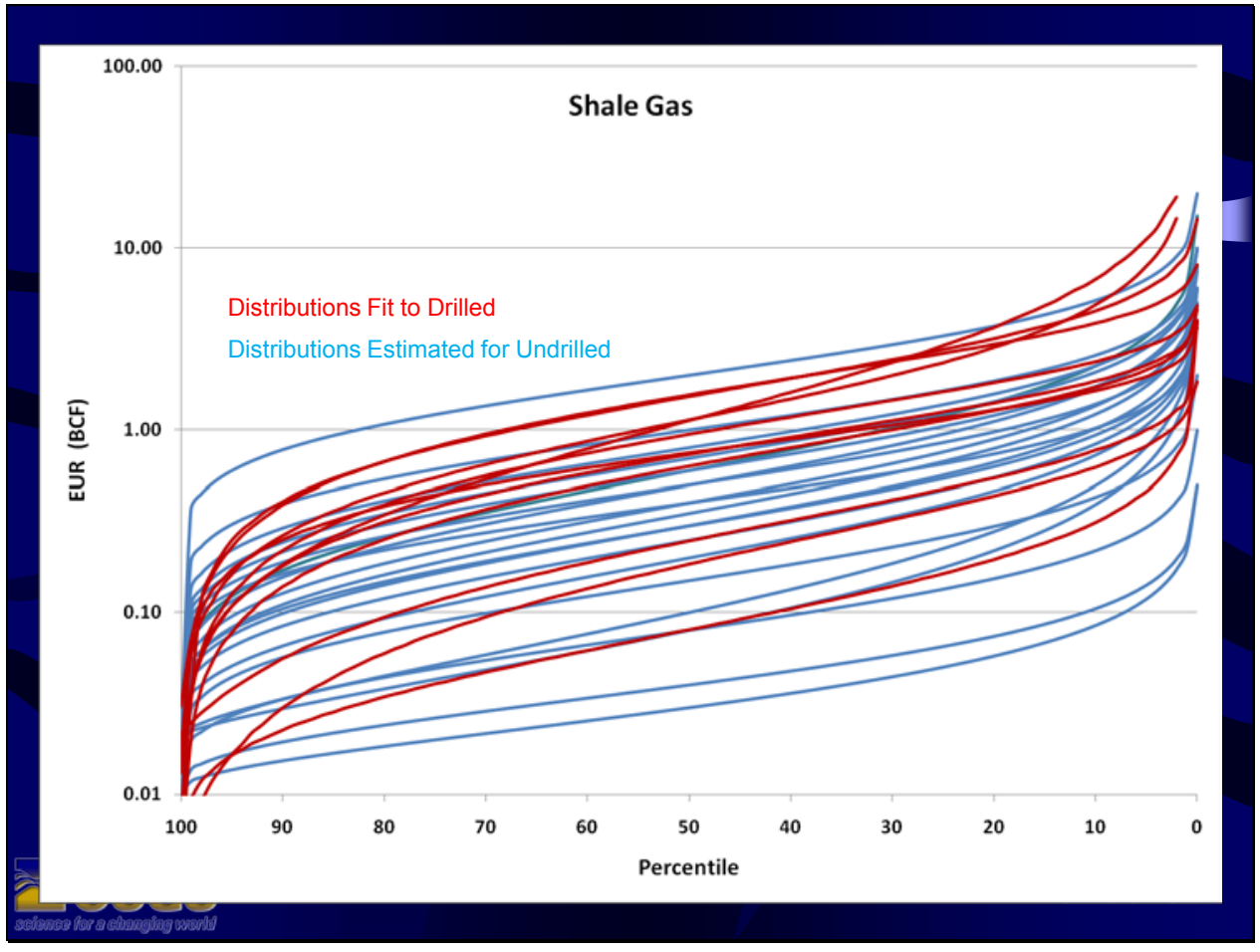

In this graph, the EUR distributions for eleven sets of shale-gas wells are plotted against the cloud to provide context. These red curves are smooth because distributions have been fitted to the data. 


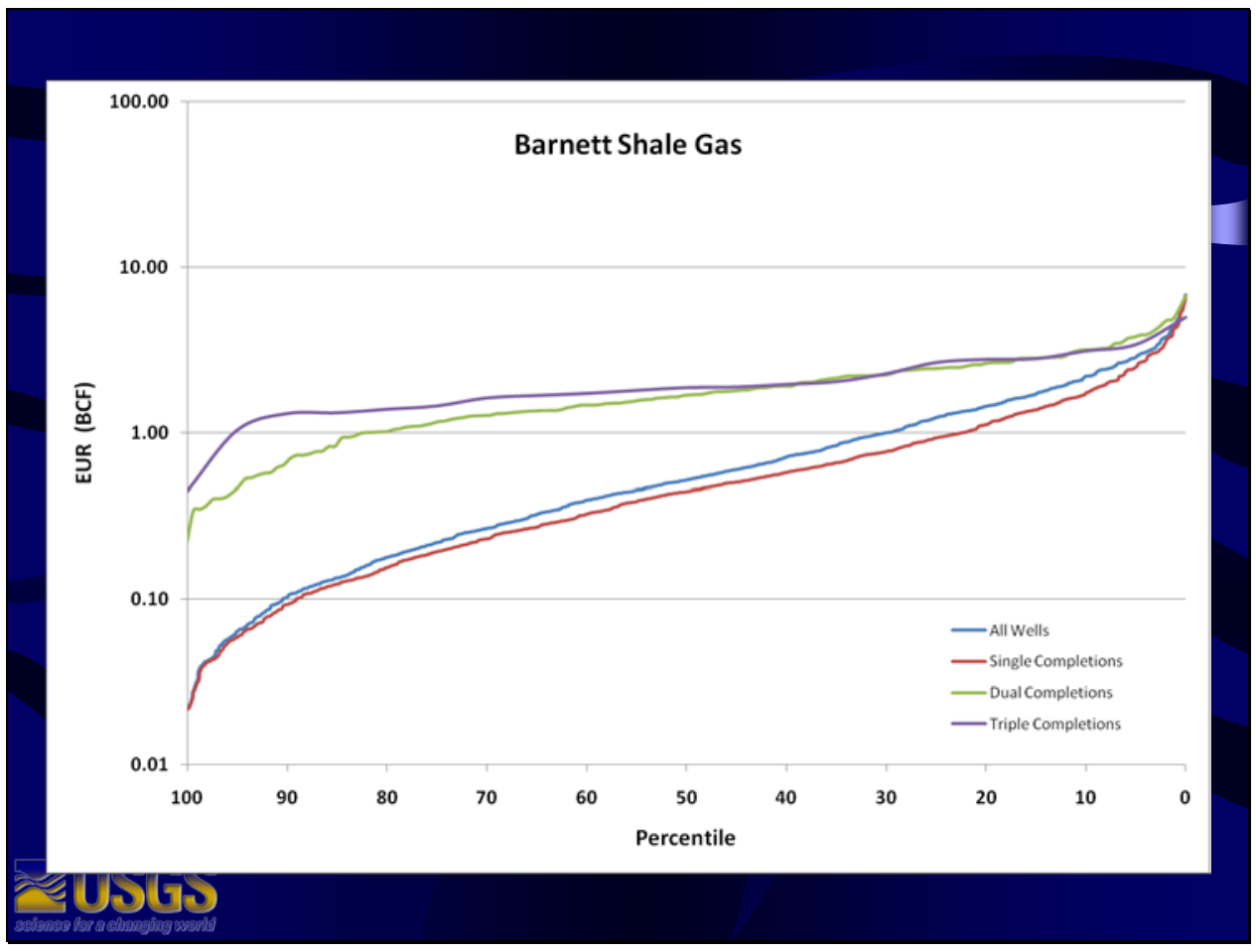

This graph presents the estimated ultimate recovery (EUR) for 1,417 vertical wells in the Barnett Shale as of 2003. It shows the distribution of EURs for those wells with an EUR of at least 0.02 bcf. The percentiles indicate what percent of the wells have an EUR of at least the indicated amount. Note that the range of EURs is greater than two orders of magnitude. This graph also has lines for single completions (1,240), dual completions (156), and triple completions (21). (1 billion cubic feet $=$ approximately 28 million cubic meters $)$. 


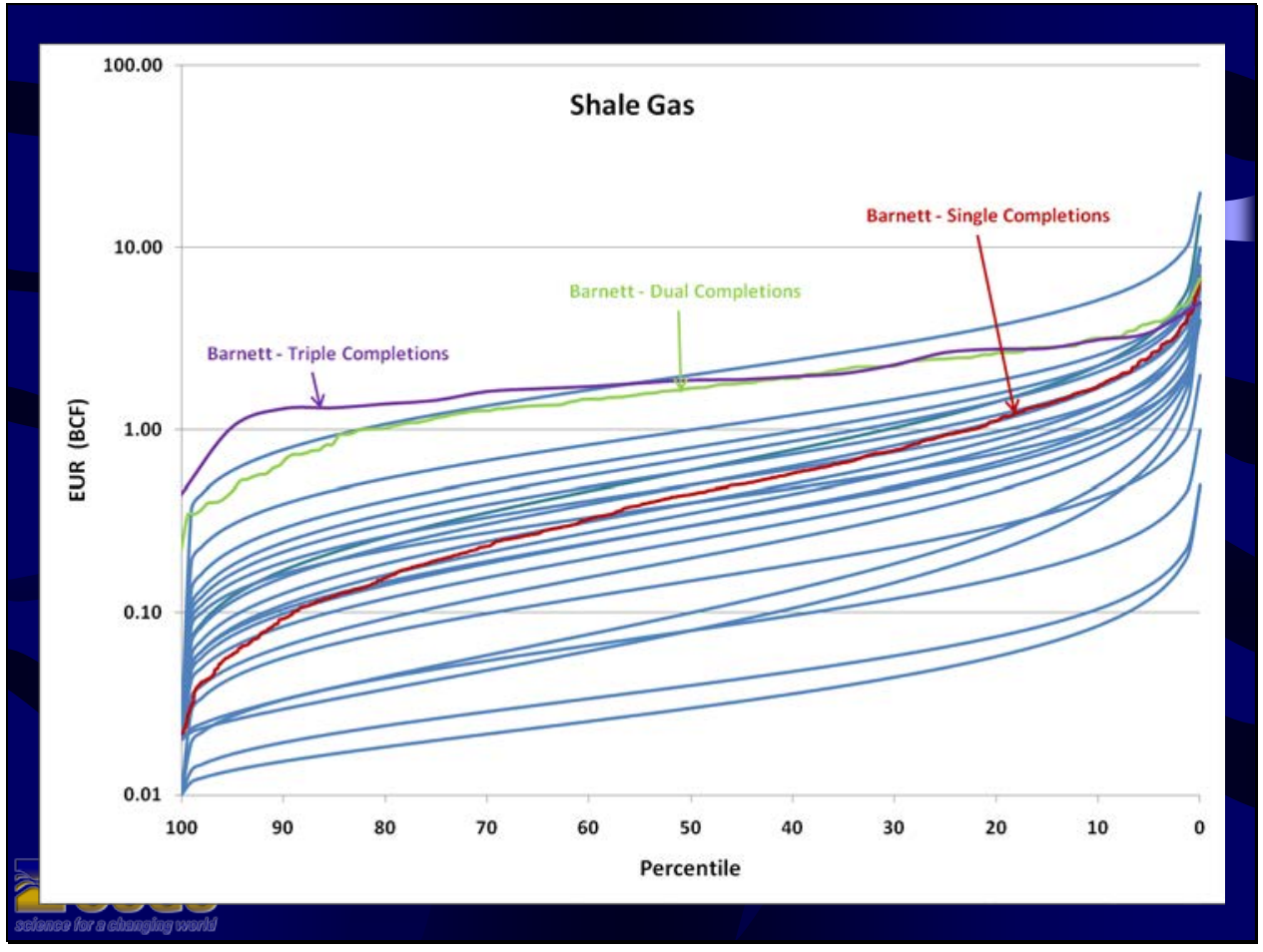

The data from the previous graph is now plotted against the cloud to provide context. 


\section{Choosing Analogs}

- Use multiple analogs, not just the single "best" analog.

- Multiple analogs give some measure of variability.

- Analogs for drainage areas and EURs must be based on similar development schemes

- For example, horizontal versus vertical wells 


\section{Modifying Analogs}

- Analogs may be modified in such cases as:

- Increased EURs where the productive section is so thick as to accommodate additional completions 


\section{Data Requirements for Shale-Gas AUs}

Again, shale gas will be used as an example to show what data should be collected and analyzed as part of an assessment. 


\section{Geologic Data}

- Where possible, data should be mapped and contoured.

- Uncertainty of data values is important.

- This is not an exhaustive list. Any other data that may be relevant to productivity should be included.

- Geologic data requirements for other continuous resources are similar. 


\section{Shale Characteristics}

- Extent of shale

- Thickness of shale

- Gross thickness

- Thickness of highly organic shale

- Structure maps 


\section{Shale Characteristics}

- Lithofacies

- Mineralogy

- Natural fractures

- Regional stress field 


\section{Shale Maturation}

- Total organic carbon content

- Organic composition

- Maturity indicators

- Thermal history models 


\section{Exploration and Production}

- Well locations

- Production tests

- Decline-curve analyses based on production histories 


\title{
Additional Information at:
}

\author{
energy.cr.usgs.gov/ \\ oilgas/noga/methodology.html
}

charpentier@usgs.gov

tcook@usgs.gov

This website has links to references concerning the revised USGS methodology, as well as references concerning previous methodologies. 